\title{
Estimation of Antarctic ozone loss from ground-based total column measurements
}

\author{
J. Kuttippurath ${ }^{1}$, F. Goutail ${ }^{1}$, J.-P. Pommereau ${ }^{1}$, F. Lefèvre ${ }^{1}$, H. K. Roscoe $^{2}$, A. Pazmiño ${ }^{1}$, W. Feng ${ }^{3}$, \\ M. P. Chipperfield ${ }^{3}$, and S. Godin-Beekmann ${ }^{1}$ \\ ${ }^{1}$ Université Versailles-Saint-Quentin, UPMC Université Paris 06, CNRS/INSU, UMR 8190 LATMOS-IPSL, Paris, France \\ ${ }^{2}$ British Antarctic Survey, Cambridge, UK \\ ${ }^{3}$ School of Earth and Environment, University of Leeds, Leeds, UK
}

Received: 5 February 2010 - Published in Atmos. Chem. Phys. Discuss.: 24 March 2010

Revised: 28 June 2010 - Accepted: 5 July 2010 - Published: 16 July 2010

\begin{abstract}
The passive tracer method is used to estimate ozone loss from ground-based measurements in the Antarctic. A sensitivity study shows that the ozone depletion can be estimated within an accuracy of $\sim 4 \%$. The method is then applied to the ground-based observations from $\mathrm{Ar}$ rival Heights, Belgrano, Concordia, Dumont d'Urville, Faraday, Halley, Marambio, Neumayer, Rothera, South Pole, Syowa, and Zhongshan for the diagnosis of ozone loss in the Antarctic. On average, the ten-day boxcar average of the vortex mean ozone column loss deduced from the groundbased stations was about $55 \pm 5 \%$ in $2005-2009$. The ozone loss computed from the ground-based measurements is in very good agreement with those derived from satellite measurements (OMI and SCIAMACHY) and model simulations (REPROBUS and SLIMCAT), where the differences are within $\pm 3-5 \%$.

The historical ground-based total ozone observations in October show that the depletion started in the late 1970s, reached a maximum in the early 1990s and stabilised afterwards due to saturation. There is no indication of ozone recovery yet. At southern mid-latitudes, a reduction of 20$50 \%$ is observed for a few days in October-November at the newly installed Rio Gallegos station. Similar depletion of ozone is also observed episodically during the vortex overpasses at Kerguelen in October-November and at Macquarie Island in July-August of the recent winters. This illustrates the significance of measurements at the edges of Antarctica.
\end{abstract}

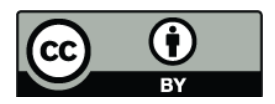

Correspondence to: J. Kuttippurath (jayan@aero.jussieu.fr)

\section{Introduction}

Stratospheric ozone has been a trace gas of great interest ever since the discovery of its dramatic decline in the Antarctic spring in early 1980s (Farman et al., 1985). Since then a string of ground-based (GB) and satellite sensors has been dedicated to observe the polar stratospheres in the framework of the international World Meteorological Organisation-Global Atmospheric Watch (WMO-GAW) programme (WMO, 1993) and the Network for Detection of Atmospheric Composition Change (NDACC) for the constant monitoring of ozone loss. Although satellites have the advantage of global coverage, they cannot observe at Solar Zenith Angle (SZA) $>84^{\circ}$ and thus not during the deep winter months. In addition, i) they have limited lifetime and cannot always be immediately replaced, ii) their measurements usually show progressive degradation, and iii) the discontinuity in the observations produce undesirable jumps in the trend analyses when the concatenated data are used. In contrast, though of limited geographical coverage, ground-based sensors offer the advantage of continuous record and easy repair or replacement if necessary. Further, those measuring at visible wavelengths, such as SAOZ (Système d'Analyse par Observation Zénithale) spectrometers used in this study, are capable of making reliable measurements until $91^{\circ} \mathrm{SZA}$, which is throughout the winter at latitudes around $65^{\circ} \mathrm{S}$. Therefore, the maintenance of an independent ground-based capacity is absolutely essential.

The passive tracer method has been successfully applied to the estimation of ozone depletion from ground-based total ozone measurements in the Arctic (Goutail et al., 1999). This approach separates the contribution due to transport

Published by Copernicus Publications on behalf of the European Geosciences Union. 
Table 1. Measurement station, latitude (Lat.), longitude (Long.), type of observation (Inst.), starting year of observation (St. yr.), and period of wintertime measurements (Obs. period) for which the ozone loss analyses are performed. The mid-latitude stations followed by the horizontal line are not considered for ozone loss analyses, but are used for the diagnosis of inter-annual variations in total ozone in the mid-latitudes.

\begin{tabular}{lllllc}
\hline Station & Lat. & Long. & Inst. & St. yr. & Obs. period \\
\hline South Pole & $89.9^{\circ} \mathrm{S}$ & $24.8^{\circ} \mathrm{W}$ & Dobson & 1963 & August/September-November \\
Belgrano & $77.9^{\circ} \mathrm{S}$ & $34.6^{\circ} \mathrm{W}$ & Brewer & 1982 & September/October-November \\
Arrival Heights & $77.8^{\circ} \mathrm{S}$ & $166.7^{\circ} \mathrm{E}$ & Dobson & 1988 & May/June-November \\
Halley & $75.6^{\circ} \mathrm{S}$ & $26.8^{\circ} \mathrm{W}$ & Dobson & 1958 & August/September-November \\
Concordia & $75.1^{\circ} \mathrm{S}$ & $123.4^{\circ} \mathrm{E}$ & SAOZ & 2007 & May/July-November \\
Neumayer & $70.7^{\circ} \mathrm{S}$ & $8.3^{\circ} \mathrm{W}$ & DOAS & 1992 & August-November \\
Zhongshan & $69.4^{\circ} \mathrm{S}$ & $76.4^{\circ} \mathrm{E}$ & Brewer & 1993 & August-November \\
Syowa & $69.0^{\circ} \mathrm{S}$ & $39.6^{\circ} \mathrm{E}$ & Dobson & 1961 & August-November \\
Rothera & $67.6^{\circ} \mathrm{S}$ & $68.1^{\circ} \mathrm{W}$ & SAOZ & 1996 & May-November \\
Dumont d'Urville & $66.7^{\circ} \mathrm{S}$ & $140.0^{\circ} \mathrm{E}$ & SAOZ & 1988 & May-November \\
Faraday/Vernadsky & $65.3^{\circ} \mathrm{S}$ & $64.3^{\circ} \mathrm{W}$ & Dobson & 1957 & August-November \\
Marambio & $64.2^{\circ} \mathrm{S}$ & $56.7^{\circ} \mathrm{W}$ & Dobson & 1987 & August-November \\
Ushuaia & $54.8^{\circ} \mathrm{S}$ & $68.2^{\circ} \mathrm{W}$ & Dobson & 1994 & May-November \\
Macquarie Isl. & $54.5^{\circ} \mathrm{S}$ & $159^{\circ} \mathrm{E}$ & Dobson & 1957 & May-November \\
Rio Gallegos & $51.6^{\circ} \mathrm{S}$ & $69.3^{\circ} \mathrm{W}$ & SAOZ & 2008 & May-November \\
Kerguelen & $49.4^{\circ} \mathrm{S}$ & $70.3^{\circ} \mathrm{E}$ & SAOZ & 1995 & May-November \\
Lauder & $45.0^{\circ} \mathrm{S}$ & $169.6^{\circ} \mathrm{E}$ & Dobson & 1970 & May-November \\
\hline Comodoro Rivadavida & $45.8^{\circ} \mathrm{S}$ & $67.5^{\circ} \mathrm{W}$ & Dobson & 1995 & May-November \\
Melbourne & $37.7^{\circ} \mathrm{S}$ & $144.8^{\circ} \mathrm{E}$ & Dobson & 1983 & May-November \\
Buenos Aires & $34.6^{\circ} \mathrm{S}$ & $58.5^{\circ} \mathrm{W}$ & Dobson & 1965 & May-November \\
Perth & $31.9^{\circ} \mathrm{S}$ & $115.9^{\circ} \mathrm{E}$ & Dobson & 1969 & May-November \\
\hline
\end{tabular}

and photochemical loss in total ozone evolution during the winter. The tracer calculations are performed by Chemical Transport Models (CTMs) in which photochemistry is deactivated to represent the dynamical evolution of the winter.

The objective of the present study is to apply the same technique to the Antarctic total ozone observations for the yearly evaluation of ozone depletion. In order to estimate the loss, we use ground-based measurements from three SAOZ stations in the Antarctic. Figure 1 shows the oldest SAOZ instrument installed in the Antarctic in 1988. Further, we use measurements from six Dobsons, two Brewers and a UVVIS (Ultra Violet-Visible) DOAS (Differential Optical Absorption Spectroscopy) spectrometer that includes observations from the historical stations Halley, Syowa, and South Pole. Table 1 and Fig. 2 show details of the stations. We use the REPROBUS and SLIMCAT global three-dimensional (3D) CTMs for the tracer simulations. The ozone loss derived from the ground-based measurements are compared to that of the space-borne observations of the Ozone Monitoring Instrument (OMI) on Aura and the Scanning Imaging Absorption Spectrometer for Atmospheric Chartography (SCIAMACHY) on ENVISAT.

We organise the article as follows: The introduction is followed by the description of ozone measurements used in this study in Sect. 2. Section 3 presents the models and the ozone loss estimation method. Section 4 details the appli-

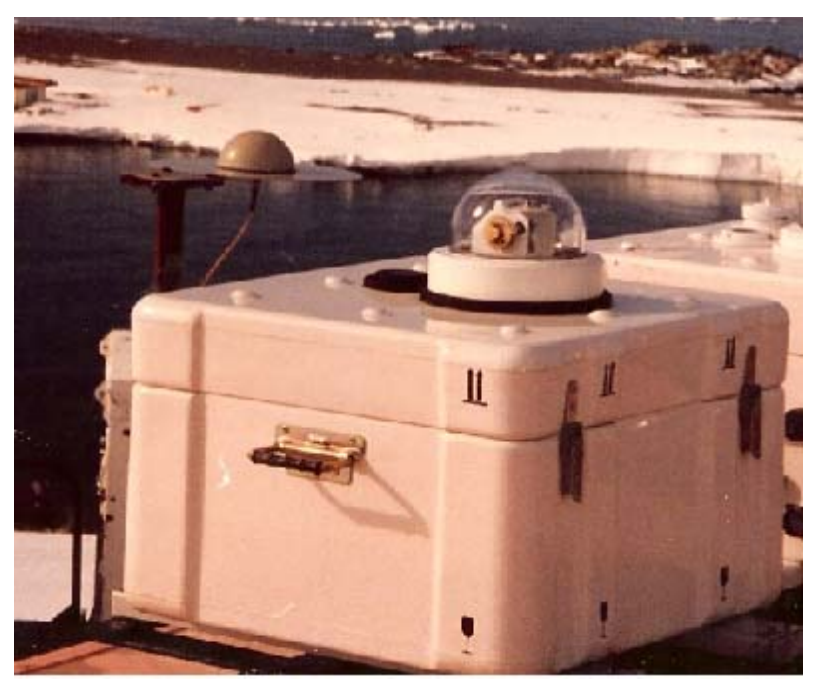

Fig. 1. The SAOZ instrument at Dumont d'Urville in the Antarctic.

cation of the method to recent Antarctic measurements and Sect. 5 gives a brief discussion on total ozone in the southern high and mid-latitudes with respect to the ozone loss analyses. Section 6 concludes the study. 


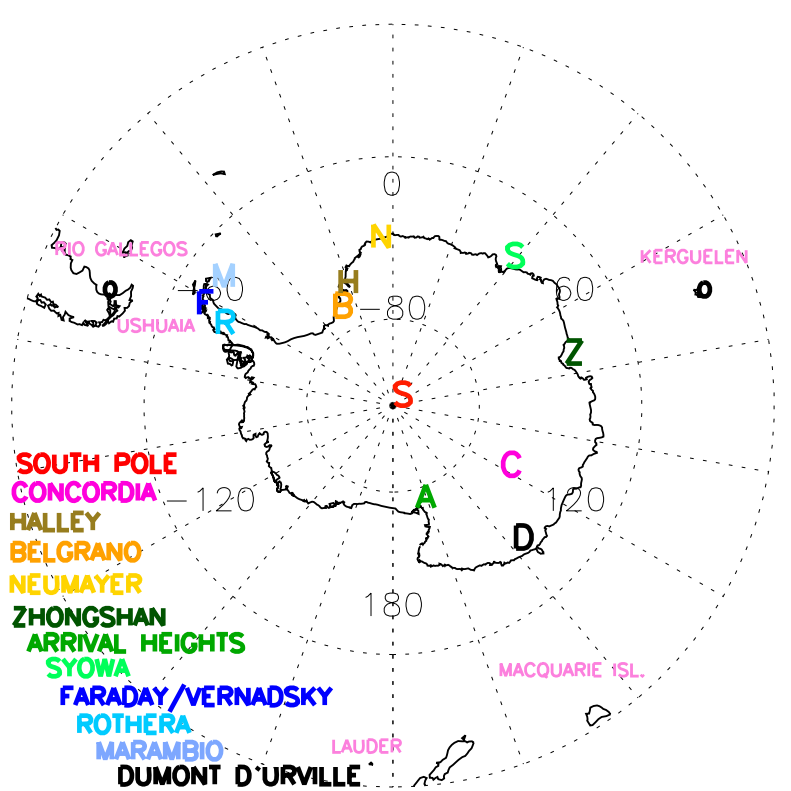

Fig. 2. The ground-based stations in the Antarctic and southern mid-latitudes considered in the ozone loss analyses. The midlatitude stations are shown in light pink colour. The positions of Antarctic stations are marked by the first letter of their names in respective colours.

\section{Ozone column observations}

\subsection{Ground-based}

\subsubsection{SAOZ}

The zenith sky SAOZ UV-VIS spectrometers (Pommereau and Goutail, 1988) operate at $300-650 \mathrm{~nm}$, looking at sunlight scattered from the zenith sky during twilight. Ozone is measured in the Chappuis band $(450-650 \mathrm{~nm})$ at high SZA between 86 and $91^{\circ}$ every morning and evening. As concluded from various inter-comparison exercises (Roscoe et al., 1999; Vaughan et al., 1997), the measurements from different SAOZ instruments are consistent within $\pm 3 \%$. The main source of uncertainty in the measurements is the air mass factor (AMF) and for instance, the difference in AMF between inside and outside the ozone hole can be up to $10 \%$.

\subsubsection{DOAS}

This is a similar instrument to $\mathrm{SAOZ}$ but with differences of detail, e.g. light is collected by a small telescope and fed to the spectrograph using two depolarising quartz fibre bundles. The spectrograph consists of a UV and a visible channel. Ozone measurements are performed in $490-555 \mathrm{~nm}$ at 84 $90^{\circ} \mathrm{SZA}$, similar to SAOZ. Ozone slant column densities are converted using AMFs estimated from AMFTRAN Monte Carlo Radiative Transfer Model. The accuracy of ozone vertical column density retrieved from the Neumayer DOAS is about $2 \%$. The DOAS measurements are described in detail by Frieß et al. (2005).

\subsubsection{Dobson spectrophotometer}

The instrument consists of a double prism monochromator to measure the differential absorption of ozone in UV (Dobson, 1957). Individual measurements are performed by looking at the direct sun by clear sky and are averaged to a daily mean. Nevertheless, those measurements are limited to SZA $<80^{\circ}$ i.e. after mid-August at the polar circle. As the instrument requires calibration, comparison with the well-calibrated Dobson \#83 (Boulder, USA) is carried out. However, calibration with this instrument may not be accurate at the South Pole (because of high latitude and large SZA) and hence, it may slightly affect the accuracy of measurements. The estimated relative error in direct sun total ozone measurements is $0.5 \%$ or $1 \mathrm{DU}$ (Basher, 1982).

\subsubsection{Brewer spectrophotometer}

Brewer measurements also make use of differential absorption in the UV region (Brewer, 1973). The determination of total ozone is similar, but sensitivity of the instrument is better than that of the Dobson. As in the case of the Dobson, an empirical relation between simultaneous direct sun and zenith sky has to be established if zenith observations are to be taken. Calibration of the instrument is essential. A well calibrated Brewer direct sun measurement has an error comparable to that of the Dobson.

\subsection{Space-borne}

\subsubsection{OMI on Aura}

The OMI sensor on the Aura satellite began to operate in 2004 as a successor to the Total Ozone Mapping Spectrometer (TOMS) (Levelt et al., 2006). The nadir viewing UVVIS spectrometer measures solar light scattered by the atmosphere with a spatial resolution at nadir of $13 \times 24 \mathrm{~km}$. The sun-synchronous orbit of Aura and the wide viewing angle of OMI enable daily global coverage of the sunlit portion of the Earth. The overpass data, spatial averages within $100 \mathrm{~km}$, are retrieved using the TOMS v8 algorithm. The retrieval makes use of two wavelengths: 331.2 and $360 \mathrm{~nm}$ for high ozone and at high SZA. However, retrievals from 317.5 and $331.2 \mathrm{~nm}$ are used for most conditions. The uncertainty of the ozone column is $2-5 \%$ for SZA $<84^{\circ}$ (Bhartia and Wellemeyer, 2002).

\subsubsection{SCIAMACHY on ENVISAT}

SCIAMACHY (hereafter SCIA), an imaging spectrometer on board ENVISAT placed into orbit in 2002, utilises nadir, limb and sun/moon occultations for ozone column retrievals (Bovensman et al., 1999). The data are recorded from the 
transmitted, back scattered and reflected solar radiation from the atmosphere at $240-1700 \mathrm{~nm}$. The instantaneous field of view spans $2.6 \mathrm{~km}$ in the vertical and $110 \mathrm{~km}$ in the horizontal direction at the tangent point. We consider the total column overpass data calculated from nadir measurements, averaged within $100 \mathrm{~km}$ radius above each station, retrieved using the v2 algorithm based on TOSOMI (Total Ozone retrieval scheme for SCIAMACHY based on the OMI DOAS algorithm). The estimated accuracy of the ozone column is about 2-3.3\% (Eskes et al., 2005).

\section{Estimation of ozone loss}

To find chemical ozone depletion from the measurements by applying the passive technique, tracer calculation by a CTM is required. For this purpose, passive ozone (ozone calculated without interactive chemistry) simulations from REPROBUS for 2006-2009 and SLIMCAT for 2005 are considered, as the data from the former was not available in 2005. We use the diurnal averages of the ozone and tracer column simulations sampled at the location of each station. Nevertheless, a detailed discussion on the model calculations is beyond the scope of this study as it focuses on the method and measurements. The details of tracer simulations in the models are given in the following sections and the method is described afterwards.

\subsection{REPROBUS}

The REPROBUS 3-D CTM has been widely utilised in previous studies of stratospheric chemistry (Lefèvre et al., 1994, 1998). It uses a hybrid $\sigma$-pressure vertical coordinate for which winds and temperatures are driven by the ECMWF operational data on 60 vertical levels to $0.1 \mathrm{hPa}(\sim 60 \mathrm{~km})$ until February 2006, and then 91 levels to $0.01 \mathrm{hPa}(\sim 90 \mathrm{~km})$ afterwards. Vertical advection is computed directly from the analysed winds. The simulations presented here were integrated on a global grid with a horizontal resolution of $2^{\circ} \times 2^{\circ}$. Chemical species are transported by a semi-Lagrangian code (Williamson and Rasch, 1989). The model includes a comprehensive description of stratospheric chemistry. Absorption cross-sections and kinetics data are based on Sander et al. (2006). However, absorption cross sections of $\mathrm{Cl}_{2} \mathrm{O}_{2}$ are taken from Burkholder et al. (1990) and are extrapolated to $450 \mathrm{~nm}$. Monthly varying $\mathrm{H}_{2} \mathrm{SO}_{4}$ fields, leading to the formation of liquid aerosols in the CTM, are computed from the outputs of a 2-D-model long-term simulation that consider impacts of volcanic eruptions. The model includes reactions on binary and ternary liquid aerosols as well as on waterice particles. The composition of liquid aerosols is calculated analytically (Luo et al., 1995). The ice particles are assumed to incorporate $\mathrm{HNO}_{3}$ in the form of nitric acid trihydrate (NAT) (Davies et al., 2002). $\mathrm{Cl}_{\mathrm{y}}$ and $\mathrm{Br}_{\mathrm{y}}$ are explicitly calculated from their long-lived sources at the surface and are therefore time dependent. An additional 6 pptv of bromine in the form of $\mathrm{CH}_{2} \mathrm{Br}_{2}$ is added to $\mathrm{Br}_{\mathrm{y}}$ to represent the contribution of brominated short lived species reaching the stratosphere (WMO, 2007).

\subsection{SLIMCAT}

SLIMCAT is an off-line 3-D CTM described in detail by Chipperfield (1999). The model uses hybrid $\sigma-\theta$ as the vertical coordinate and extends from the surface to a top level which depends on the domain of the forcing analyses (Feng et al., 2007a). Here the horizontal winds and temperatures are specified using ECMWF operational data of 60 vertical levels to $0.1 \mathrm{hPa}$. Vertical advection in the $\theta$-domain (above $350 \mathrm{~K}$ ) is calculated from diabatic heating rates using the National Centre for Atmospheric Research Community Climate Model radiation scheme (Feng et al., 2005b; Chipperfield, 2006). Chemical tracers are advected by conservation of second-order moments (Prather, 1986). The model describes the main stratospheric chemical species $\mathrm{O}_{\mathrm{x}}, \mathrm{HO}_{\mathrm{x}}, \mathrm{NO}_{\mathrm{y}}, \mathrm{Cl}_{\mathrm{y}}$, $\mathrm{Br}_{\mathrm{y}}$ as well as source gases and a treatment for $\mathrm{CH}_{4}$ oxidation. It contains a detailed gas-phase stratospheric chemistry scheme. As in REPROBUS, the photochemical data are based on Sander et al. (2006) and the absorption cross sections of $\mathrm{Cl}_{2} \mathrm{O}_{2}$ are taken from Burkholder et al. (1990), which are extrapolated to $450 \mathrm{~nm}$. The model treats heterogeneous reactions on liquid aerosols, NAT and ice (Chipperfield, 1999), and denitrification schemes (Davies et al., 2002). An extra 6 pptv of bromine reaching the stratosphere from short-lived species is also included in the calculations (Feng et al., 2007b; WMO, 2007).

\subsection{The passive tracer method}

The ozone loss by the passive method is computed by subtracting passive ozone from measured ozone. Large changes in total ozone inside polar vortex are related to convergence or divergence due to changes in tropopause height, planetary wave induced adiabatic motions and diabatic descent due to radiative cooling. To find the ozone depletion inside the vortex, the Nash et al. (1996) criterion is applied to find the vortex limit [maximum of the first derivative of potential vorticity $(\mathrm{PV})]$. A sensitivity test was conducted using the criterion of $35 \mathrm{PV}$ units (pvu) and $45 \mathrm{pvu}$ (1 pvu is $10^{-6} \mathrm{Km}^{2} \mathrm{~kg}^{-1} \mathrm{~s}^{-1}$ ). While the low $\mathrm{PV}$ criterion adds noise, the high PV criterion makes the data sparse. As expected, though there were differences in number of observations inside the vortex when using different criteria, the final results were similar. Therefore, the Nash et al. (1996) criterion is adopted after exempting some apparent noise in the vortex limit data. The PV data used to differentiate the vortex measurements were generated from the MIMOSA contour advection model (Hauchecorne et al., 2002) forced by the ECMWF meteorological analyses. 


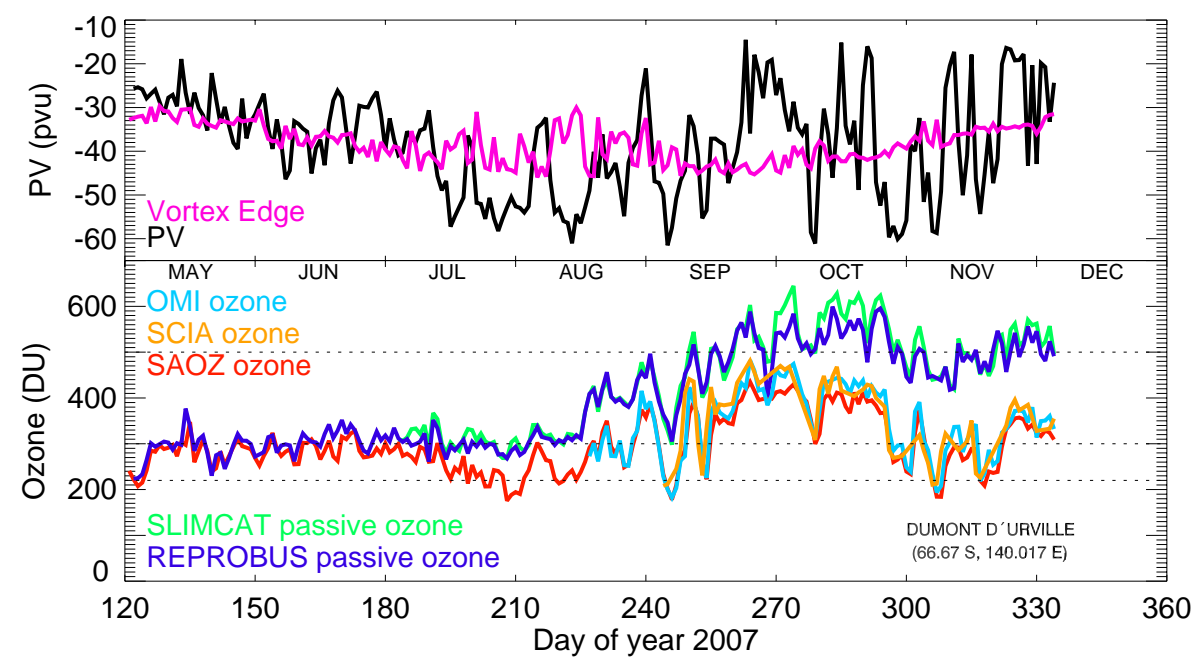

Fig. 3. Temporal evolution of various parametrs used for the computation of ozone loss at Dumont d'Urville in 2007. Top: ECMWF potential vorticity at $475 \mathrm{~K}$ (black), and polar vortex edge (magenta). Bottom: SAOZ (red), OMI (cyan) and SCIA (yellow) daily mean total ozone and SLIMCAT (green) and REPROBUS (blue) passive ozone (tracer). The horizontal bars represent the 220 DU ozone hole criterion, the 300 DU average pre-ozone hole value, and the 500 DU average spring column in the absence of depletion.

The vortex edge calculated at $475 \mathrm{~K}$, where the concentration of ozone has its maximum in spring, is selected for its loss estimation. The ozone loss analysis starts in July and it extends until November.

Figure 3 illustrates the basics of the tracer scheme with relevant data at Dumont d'Urville for the winter 2007. The day-to-day variations due to vortex positions are well captured by the measurements and simulations. From July onwards, the ozone values inside the vortex decrease with time while they increase outside. The ozone columns, both measured and calculated, are anti-correlated with the PV values, where the high PV corresponds to the low ozone in the vortex. The SAOZ observations are continuous throughout the winter at Dumont d'Urville, while both OMI and SCIA start in mid-August and thus miss the onset of ozone loss process. Nevertheless, the observations from both ground and space are very consistent afterwards.

The chemical ozone loss is then computed by finding the difference between the tracer simulated by the CTM and ozone measured from the ground or space. That is, the observed ozone loss in absolute unit (DU) is estimated as ozone $_{\text {meas }}$-tracer and in relative unit (\%) is computed as $100 \times\left(\right.$ ozone $_{\text {meas }}$-tracer $) /$ tracer. This procedure is repeated for each station and then sorted for inside the vortex. The example of 2007 is given in Fig. 4. The ozone loss starts at the edge of the vortex in early-July, when it is displaced to the sunlit latitudes. So the stations at the edge, such as Dumont d'Urville and Rothera, are subjected to ozone loss early in the winter (e.g. Lee et al., 2000). As the day gets longer and light penetrates deeper inside the continent, the stations Concordia and Arrival Heights followed by Neumayer, Halley, Syowa, Belgrano and South Pole undergo ozone deple- tion (e.g. Chubachi, 2009). Measurements at the latter stations were possible only in late-August or September. The figure clearly shows the late winter start of ozone depletion in the vortex core, Concordia in particular (South Pole measurements start even later, by mid-September, e.g. Solomon et al., 2005). This delayed onset also produces a step like feature in the mean ozone loss curves in the July to mid-August period.

The intensity of ozone destruction is also connected to the position of the stations and axis of the vortex. For instance, the sites well inside the vortex experience more loss than those at the edge. Therefore, South Pole or Belgrano observe more severe loss than Dumont d'Urville in each winter. The loss at Concordia is less than that of South Pole and larger than that of Dumont d'Urville due to the strength and longevity of the vortex over the respective locations.

The results delineate three distinct phases of the Antarctic ozone loss as marked with dotted vertical lines and colour shades in Fig. 4. The first stage starts in July and ends in late-September, where rapid loss occurs with return of the sun over the continent. The loss rate is largest in this period. Starting time of this phase varies from May to July depending on the temperature, the time of vortex formation and its location. if the temperature is relatively cold and the vortex appears in early winter that shifted in latitude, there can be some loss in May-June and thus this phase may start in May. The cumulative maximum of the ozone loss is generally observed in early-October, afterwards the depletion stops when PSCs (Polar Stratospheric Clouds) are no longer forming because of comparatively higher temperatures. This is the second phase of the ozone loss processes, where depth of the ozone hole reduces then more or 


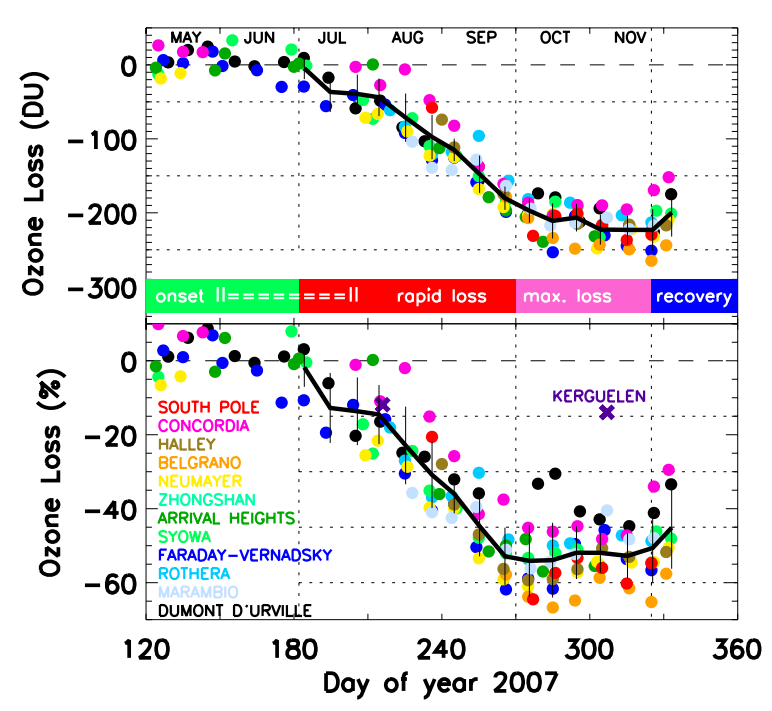

Fig. 4. Vortex averaged (ten-day mean) individual ozone loss estimated at the ground-based stations in the Antarctic using the passive method (top: DU, bottom: percent). The loss in absolute unit (DU)

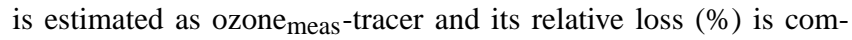
puted as $100 \times\left(\right.$ ozone $_{\text {meas }}$-tracer $) /$ tracer. The black thick lines represent the mean and the error bars represent the standard deviation from the mean. The observations from Kerguelen, a mid-latitude station, are not included in the average, shown with " $x$ " marks. The vertical dotted lines represent the different phases of ozone loss processes in the Antarctic as marked in the colour shades (see text), while the horizontal dotted lines represent 50, 150 and 250 DU and $15,30,45$ and $60 \%$ of ozone loss. Some stations start the wintertime observation in August or September. The ozone loss onset varies with respect to sunlit latitudes and therefore, the onset period depends on co-ordinates of the stations. Thus, the onset and rapid loss phases are clustered together with dashed lines.

less slowly depending on vortex erosion, exchange with midlatitudes, and location of the station. Therefore, the edge stations, i.e. Dumont d'Urville, Marambio and Rothera, recover more rapidly. The ozone hole is not homogeneous. Depending on the location of the station with respect to the vortex, the loss can vary within $\pm 10 \%$ ( $\pm 20 \mathrm{DU}$ ). In the third phase, the ozone hole disappears in general by the end of November or early-December as in 2006, except in the case of the unprecedented vortex split in 2002. It is during this period (October-November) that vortex pieces or filaments more or less filled-in could be observed at lower latitudes as in Kerguelen at $49^{\circ} \mathrm{S}$ in present case.

\subsection{Error analysis}

In order to investigate the uncertainty of the method, ozone loss under various conditions are analysed. Figure 5 shows the ozone depletion estimated with SAOZ, OMI and SCIA using REPROBUS and SLIMCAT (with both T42 and T21 resolution) tracer for Dumont d'Urville in 2007. The stations at the edge region (Lee et al., 2000) show more spread than

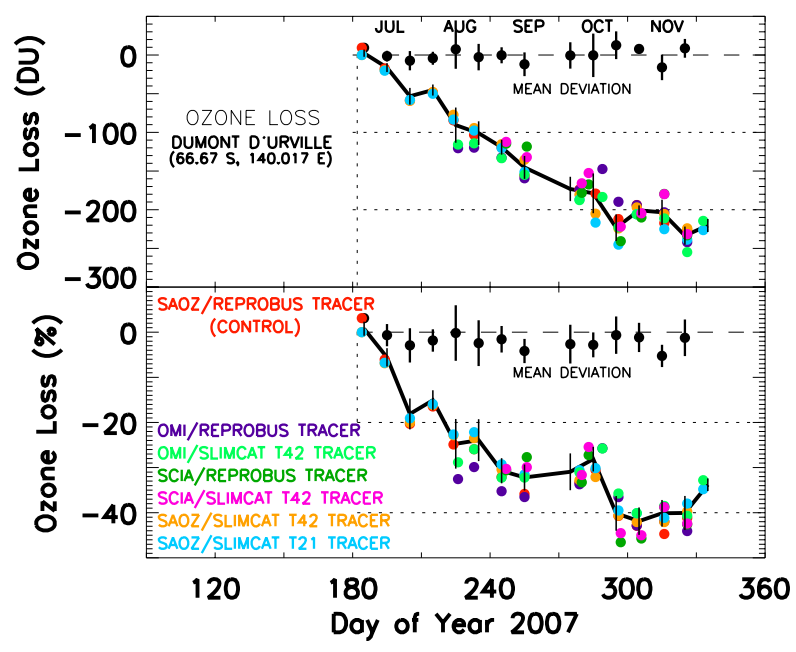

Fig. 5. Vortex averaged (ten-day mean) ozone loss diagnosed using different measurements and various tracer calculations by different model setups at Dumont d'Urville (top: DU, bottom: percent). The loss in absolute unit (DU) is estimated as ozone meas-tracer and its relative loss $(\%)$ is computed as $100 \times\left(\right.$ ozone $_{\text {meas }}$-tracer $) /$ tracer. The black solid lines represent the mean ozone loss from all scenarios and the black filled-circles represent the average deviation from the control (SAOZ/REPROBUS tracer). The error bars represent the standard deviation from the mean. The dotted vertical line represents 1 July. The dotted horizontal lines represent 100 and $200 \mathrm{DU}$ and 20 and $40 \%$ of ozone loss.

those inside the vortex (for which Dumont d'Urville shows the largest). We use the SAOZ/ground-based ozone loss analysis with REPROBUS tracer using Mimosa PV and Nash vortex edge as the control, since simulated results match well with the measurements. To compute the uncertainty, the difference between the control and the ozone loss was estimated with other setups, as shown in the figure. The root sum square (RSS) of all these differences as well as the uncertainties in the measurements yield a deviation up to $4.4 \%$ (0-21 DU) depending on day.

The RSS computation includes all prime processes that affect the accuracy of the method. Those are: i) the systematic differences between the instruments, drop in measured ozone due to presence of PSCs, and difference in AMF profile shapes (considered in the analysis by including the measurement uncertainties of respective instruments), ii) differences in simulated profiles with measurements when ozone varies rapidly (considered in the analysis by using tracers from different models of varying horizontal and vertical resolution), and iii) shifts in location of estimated vortex edge (considered in the analyses by testing with different vortex edge criteria, PV data sets and horizontal resolution of the models). Since size of the vortex can be smaller above the ozone loss analysis level of $475 \mathrm{~K}$, air outside the vortex cannot be ruled out and was not possible to account for by these experiments. 


\subsection{Conclusions on the method}

There are a few parameters that influence the strength of ozone loss evaluation method. The most evident are the realism of the tracer field in the models and the vortex edge calculation from potential vorticity. We tested how the derived ozone loss varies with the expected changes in these parameters. These tests were repeated for the overpass measurements from satellite observations. The RSS of the deviations including measurement accuracies is within $4 \%$. Since accuracy of the measurements is in the order of $3-5 \%$ and the total error derived from RSS is $\sim 4 \%$, the small contribution from other input shows the consistency and potency of the method. In addition, the use of different model setups for the calculations of tracer ensures that the estimation provides consistent results and affirms that the method is sound. The main dispersion of loss computation comes from the inhomogeneous distribution of ozone in the vortex, which ranges from $\pm 2-10 \%$ at the beginning when only the edge stations are exposed to sunlight, to $\pm 0-5 \%$ at the end when depletion has stopped.

\section{Application of the method: Antarctic winters 2005- 2009}

We now examine the variability of the Antarctic ozone loss between 2005 and 2009. The ozone loss analyses using SCIA observations exclude South Pole measurements because of their unavailability. The daily ozone depletion rates are calculated in a common time window for all data sets, i.e. between day 225 and 275 in each winter. Figure 6 shows the ten-day boxcar average of the vortex mean ozone loss derived from the ground-based, OMI, SCIA and model (REPROBUS for the winters 2006-2009 and SLIMCAT in 2005) data for the recent winters and we begin the discussion with the most recent year. In order to preserve the temporal ozone loss features, instead of finding the vortex averaged depletion at each station in every ten days, the average of ozone and tracer data inside the vortex from all stations are considered here. Then the observed ozone loss in absolute unit (DU) is estimated as ozone ${ }_{\text {avg }}$-tracer $_{\text {avg }}$ and in relative unit (\%) is computed as $100 \times\left(\right.$ ozone $_{\text {avg }}-$ tracer $\left._{\text {avg }}\right) /$ tracer $_{\text {avg }}$. Here, the ozone ${ }_{\text {avg }}\left(\right.$ tracer $_{\text {avg }}$ ) represents the mean of the ozone (tracer) data inside the vortex from all stations. The same approach is repeated for the model simulations.

In 2009, the ozone depletion started by the first week of July and it peaked to $53 \%$ by late-September. The satellite observations, both OMI and SCIA, agree well with the ground-based analysis. The ozone loss rate shows 0.62 for ground-based, 0.58 for OMI, 0.54 for SCIA and $0.55 \%$ /day for the model. Further details of the analyses are listed in Table 2.

In 2008, the ground-based measurements find the ozone loss onset in early July and its maximum in early Octo-
Table 2. Vortex averaged ozone loss (ten-day boxcar average) estimated from the ground-based (GB), OMI and SCIAMACHY (SCIA) observations and the total column integrated from REPROBUS (2006-2009) and SLIMCAT (2005) simulations (MODEL), during recent Antarctic winters. Extrapolated data are used for day 225 to calculate the ozone loss rates in 2007 and 2009 from SCIA.

\begin{tabular}{llllcc}
\hline Year & Data & \multicolumn{2}{c}{ Max. loss } & \multicolumn{2}{c}{ Loss rate (day) } \\
& & DU & $\%$ & DU & $\%$ \\
\hline \multirow{4}{*}{2009 GB } & 205 & 53 & 2.41 & 0.62 \\
& OMI & 240 & 53 & 2.28 & 0.58 \\
& SCIA & 217 & 51 & 2.16 & 0.54 \\
& MODEL & 210 & 54 & 2.22 & 0.55 \\
& GB & 227 & 59 & 3.22 & 0.84 \\
2008 & OMI & 240 & 60 & 3.37 & 0.88 \\
& SCIA & 237 & 57 & 2.52 & 0.68 \\
& MODEL & 238 & 60 & 3.00 & 0.77 \\
& GB & 228 & 55 & 2.45 & 0.62 \\
2007 & OMI & 232 & 55 & 2.35 & 0.54 \\
& SCIA & 222 & 52 & 1.76 & 0.47 \\
& MODEL & 228 & 58 & 2.60 & 0.66 \\
& GB & 179 & 56 & 2.25 & 0.71 \\
2006 & OMI & 177 & 55 & 2.08 & 0.65 \\
& SCIA & 176 & 53 & 1.85 & 0.58 \\
& MODEL & 174 & 53 & 2.26 & 0.71 \\
& GB & 245 & 61 & 2.23 & 0.53 \\
2005 & OMI & 234 & 58 & 2.12 & 0.50 \\
& SCIA & 244 & 60 & 1.72 & 0.50 \\
& MODEL & 249 & 63 & 3.06 & 0.75 \\
\hline
\end{tabular}

ber, about 59\%. Similar results are found in the loss computed from satellite and model data, where the differences are within $\pm 2 \%$. The loss rates analysed from the measurements and simulations exhibit similar values of about $0.8 \%$ /day, but slightly less from the SCIA observations.

In 2007, as found in other winters, the depletion started in July and reached its peak by mid-October. The loss derived from ground-based and OMI observations exhibit a similar maximum of $\sim 55 \%$, whereas it is $3 \%$ less with SCIA and $3 \%$ more with the model. The ozone depletion rates computed from different data sets show 0.62 for ground-based, 0.54 for OMI, 0.47 for SCIA and $0.66 \% /$ day for the model.

In 2006, the observed ozone depletion shows its onset in early July. The maximum loss derived from groundbased observations shows $56 \%$ by early October, consistent with that of OMI measurements. The loss computed from the SCIA and model data show slightly lower values of about $53 \%$. The simulated loss in July-September is slightly smaller than that of the ground-based observations, even if both return similar loss rates of $0.71 \% /$ day.

In 2005, a large loss was measured in early winter and its maximum in early-October. The peak depletion derived 

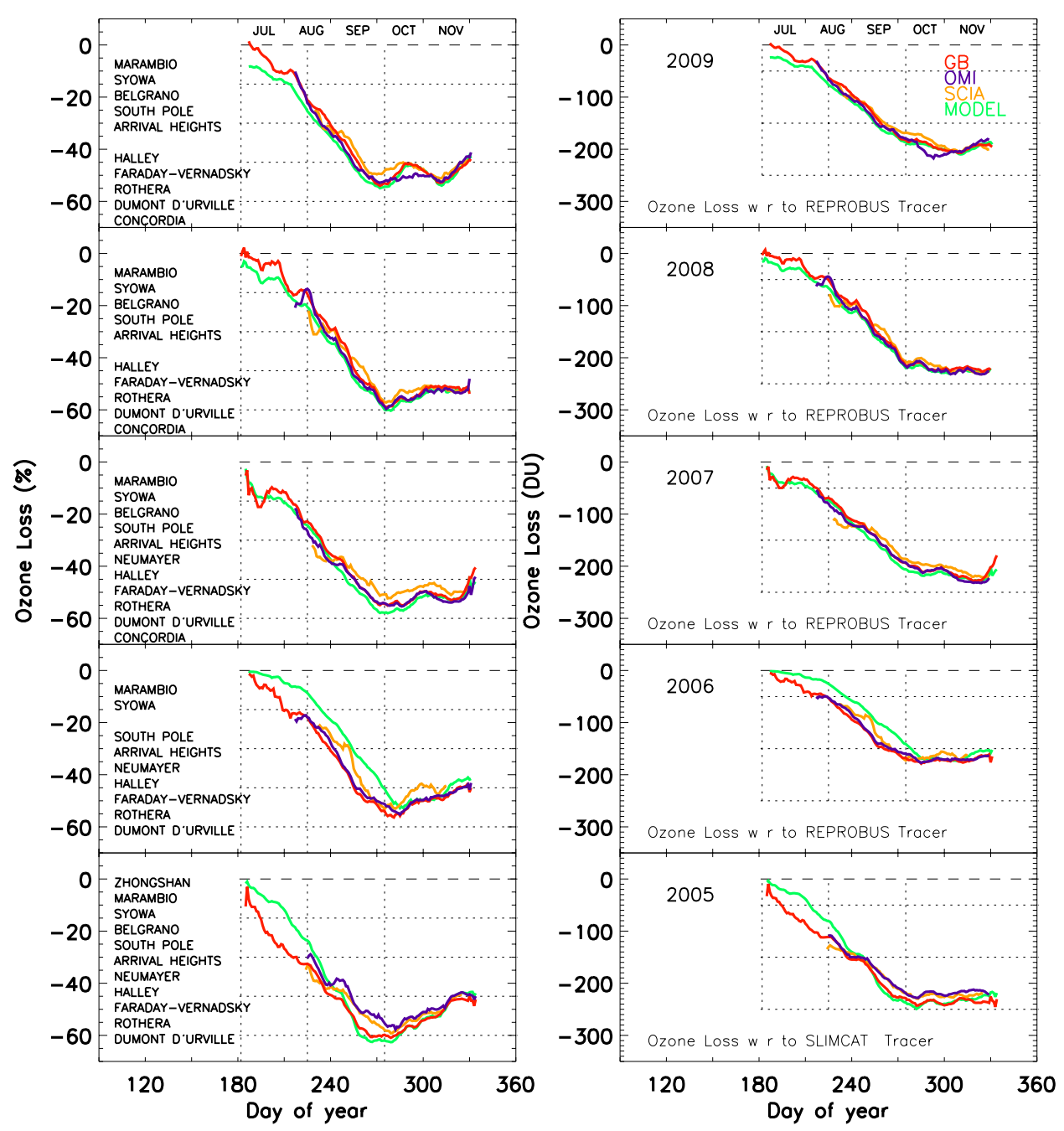

Fig. 6. Vortex averaged (ten-day boxcar average) ozone loss estimated from the ground-based (GB) measurements (as listed in the plots) in red, the OMI observations in blue (OMI), the SCIAMACHY measurements in dark yellow (SCIA) and the model simulations by REPROBUS in 2006-2009 and SLIMCAT in 2005 in green (MODEL) for the Antarctic winters 2005-2009 (Left: percent, right: DU). The loss in absolute unit (DU) is estimated as ozone $\mathrm{avg}-$ tracer $_{\mathrm{avg}}$ and its relative loss (\%) is computed as $100 \times\left(\right.$ ozone $_{\text {avg }}-$ tracer $\left._{\text {avg }}\right) /$ tracer $_{\text {avg }}$. The ozone $_{\text {avg }} /$ tracer $_{\text {avg }}$ represents the average of the measurements/simulations inside the vortex from all stations. The SCIA average excludes South Pole measurements due to unavailability. The dotted vertical lines represent day 182 ( 1 July), and day 225 and 275 , the time window used for the computations of daily ozone loss rates. The horizontal lines represent 15, 30, 45 and 60\%, and 50, 150 and 250 DU.

from the ground-based measurements is $61 \%$, whereas it is $1 \%$ more from the model calculations. The loss evaluated from satellite observations find agreeable results within \pm 2 $5 \%$. The estimated loss rates are $0.53,0.5,0.5$ and $0.75 \%$ /day for ground-based, OMI, SCIA and SLIMCAT respectively.

\section{Inter-annual variability}

In this section, we discuss the inter-annual variability of ozone loss and ozone in the southern high and mid-latitudes. The passive method used for the estimation of ozone loss depends largely on tracer simulations in the models. Therefore, a survey with ozone column measurements is necessary to analyse the consistency of the loss evaluation. Since measurements are available for decades, this diagnosis is not restricted to 2005-2009, as in the case of ozone loss estimation. However, a rigorous statistical analysis, for instance, as done by Vyushin et al. (2007) for the high latitudes or Andersen and Knudsen (2006) for the northern mid-latitudes, is beyond the scope of this work and will not be attempted.

\subsection{Antarctic ozone loss}

The general behaviour of ozone loss with time and chemistry is alike in all winters. However, the cumulative loss, period 
of maximum depletion and longevity of the ozone hole alter in accordance with the strength of the vortex. In general, as found in previous studies the Antarctic ozone depletion starts in early-July and stops during the last week of September (Solomon et al., 2005; Tilmes et al., 2006; Huck et al., 2007) except in 2006 when it extended until the first week of October. In all years the ozone hole could be followed until the $3^{r d}$ and $4^{\text {th }}$ week of November (Bevilacqua et al., 1997; Solomon et al., 2005).

Figure 7 illustrates the daily minimum temperature from ECMWF within $50-90^{\circ} \mathrm{S}$ at $475 \mathrm{~K}$ for 2005-2009. In general, temperatures below the formation of NAT $\left(T_{\mathrm{NAT}}\right)$ are found from mid-May until October. Temperatures below the freezing point of water-ice $\left(T_{\mathrm{ICE}}\right)$ occur from June to lateSeptember. Among the last four winters, 2007 shows the lowest temperatures in May-June, 2008 shows the lowest in mid-July to mid-August and 2006 shows the lowest in midSeptember to November. The recent winter 2009 was generally colder than 2008 and 2005, while the winter 2007 had the warmest September-November and earliest vortex dissipation. The winter 2006 was one of the coldest, in which the breakdown of the vortex was observed in December.

As expected from their similar temperatures, the cold winters 2006, 2008 and 2009 show little difference in ozone loss. The maximum ozone loss was found early in 2006 as compared to other winters because of the colder temperatures and well formed early vortex, whereas the warm winter 2007 shows relatively lower loss. The ozone loss evaluation from the ground and space is very consistent, showing small differences, within $\pm 2 \%$. The model calculations also find similar scales of ozone depletion in each winter, where the differences with observations are about $\pm 3-5 \%$. Though the deviations are small, the geographical differences in sampling among the ground-based, satellite and the model data could also contribute to this offset. When compared to other winters, the loss calculated from the model underestimates the measured loss in 2006. There were no changes in the model run input other than the ECMWF meteorological data used in this year as compared to other years. Therefore, the differences could be due to the possible inaccuracies in the temperature data [e.g. Boccara et al. (2008); Pitts et al. (2007)], which in turn affect PSCs, chlorine activation and hence, ozone calculations by the model.

There are no other ozone loss estimations available for the Antarctic winters 2005-2009 to compare with our results. The available studies for the previous winters are not directly comparable as they use either partial columns or a different evaluation method. However, as concluded in WMO (2007) and references therein, it is clear that Antarctic ozone depletion has stabilised in the 1995-2005 decade because of its saturation, i.e. due to the complete destruction of ozone over a broad vertical layer in the lower stratosphere. Therefore, most of the inter-annual variability results more from levels of dynamic forcing than a change in levels of Equivalent Effective Stratospheric Chlorine (EESC)

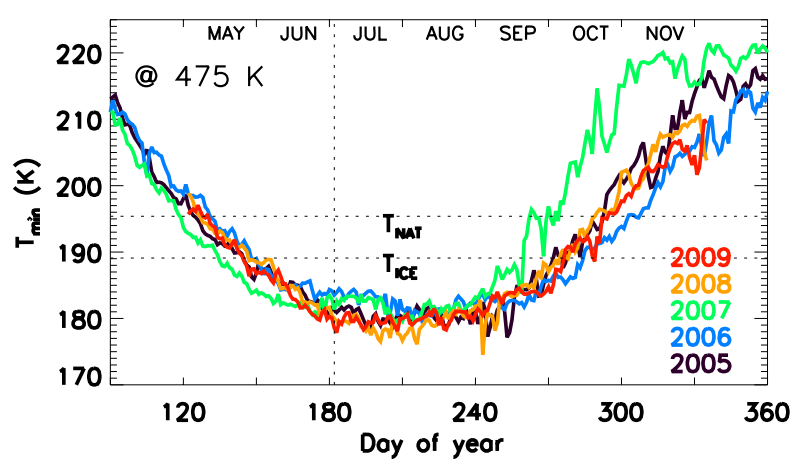

Fig. 7. ECMWF daily minimum temperatures within $50-90^{\circ} \mathrm{S}$ at $475 \mathrm{~K}$ for $2005-2009$. The horizontal lines represent the $T_{\mathrm{NAT}}$ and $T_{\text {ICE }}$ thresholds. The dotted vertical line represents 1 July.

[e.g. Yang et al. (2008)]. The amplitudes of total loss reported in 1995-2005 are very similar to that derived in 20052009. For instance, the partial column loss estimated at 350-600 K from Improved Limb Atmospheric Spectrometer (ILAS) measurements by applying the tracer correlation approach was $157 \pm 17$ DU in early-October 2003 (Tilmes et al., 2006), which is close to our evaluation for the recent winters during the same period. Our conclusion on the interannual variability of ozone loss is also in line with the previous studies (Hofmann et al., 1997; Wu and Dessler, 2001; Bevilacqua et al., 1997; Solomon et al., 2005; Hoppel et al., 2005; Lemmen et al., 2006; Huck et al., 2007). The studies based on ozonesonde observations (for e.g. South Pole and Syowa) in the Antarctic have some significance in this context as we have used measurements from these stations for our evaluations [e.g. Hofmann et al. (1997); Solomon et al. (2005)]. Additionally, the ozone loss rates in September derived from the South Pole ozone soundings in 1990s (Hofmann et al., 1997) and that estimated from the SLIMCAT simulations in early 2000s (Feng et al., 2005a) are respectively $2-3$ and 2.6-3.2 DU/day. The loss rates found in our study are also by the same order of magnitude (23 DU/day or $0.6-0.9 \% / d a y)$, which reiterates the small interannual variability of the Antarctic ozone loss.

\subsection{Southern high latitude total ozone}

Figure 8 displays the October mean of total ozone from various stations together with EESC in the Antarctic. The four historic stations Halley, Syowa, South Pole and Faraday have measurements since 1956. These observations show large decrease in total column ozone until early 1990s and saturation of the loss afterwards (WMO, 2007). The little interannual variation due to the saturation is clearly evident after mid-nineties. These results are in very good agreement with previous works on total ozone trends in the Antarctic (Bojkov and Fioletov, 1995; Bojkov et al., 1995; Bodeker et al., 2001; Fioletov et al., 2002; Kane, 2008). The above-mentioned 


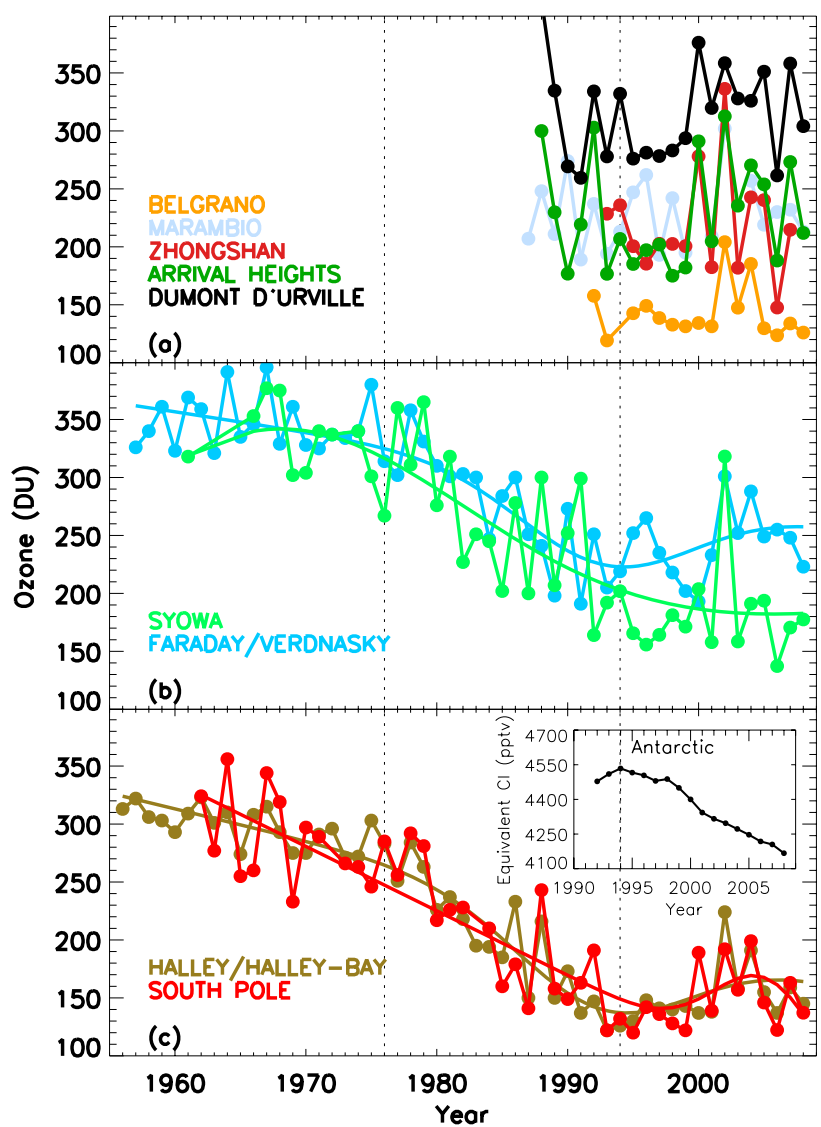

Fig. 8. Evolution of October mean total ozone in the Antarctic from ground-based observations. (a) Stations installed after 1985, (b) historical stations Syowa and Faraday, and (c) historical stations South Pole and Halley and the equivalent chlorine in the Antarctic in the inset. The historical data are plotted separately for clarity reasons. The dotted vertical lines represent years 1976 and 1994. A Gaussian fit is shown in the time series of the historical stations.

works are especially noteworthy here as we also present similar results for South Pole, Syowa, Halley and Faraday, and thus a very consistent evaluation of inter-annual variation of total ozone in the Antarctic. Even if the current negative trends in EESC sustain in the coming years, studies indicate that it will take several decades to appear ozone recovery signals in the Antarctic (e.g. Vyushin et al., 2007; Yang et al., 2008).

\subsection{Southern mid-latitude total ozone}

The ozone loss analysis for the Antarctic would not be complete without assessing its impact on mid-latitudes. Therefore, we now examine the ozone loss computed above three stations located at three different regions in southern midlatitudes. This diagnosis is particularly important since very low ozone of around 250 DU was observed on some days at these stations during recent winters. Figure 9 shows the

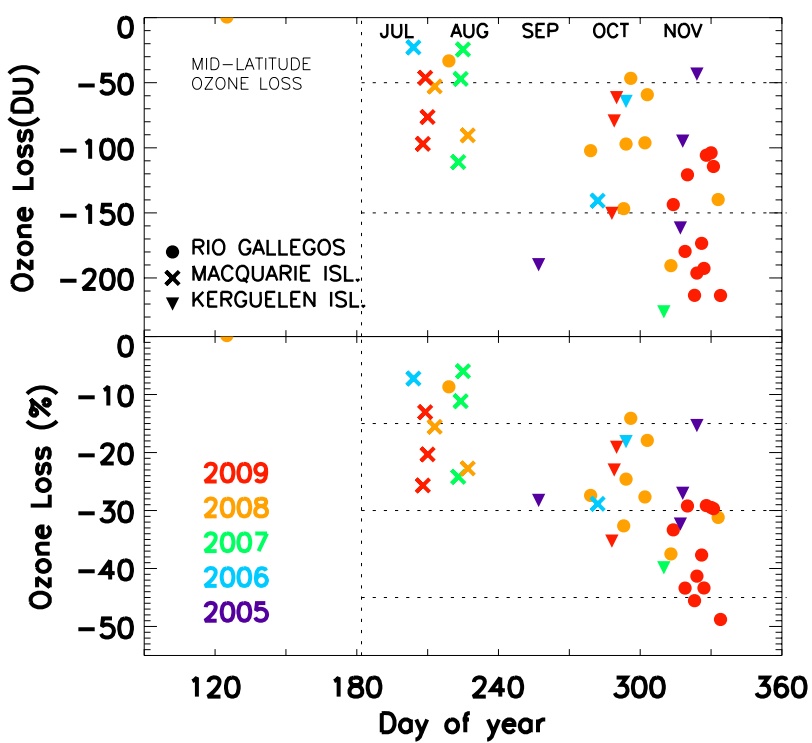

Fig. 9. Ozone loss estimated during the vortex events at selected southern mid-latitude stations for the recent Antarctic winters (Top: DU, bottom: percent). The loss in absolute unit (DU) is esti-

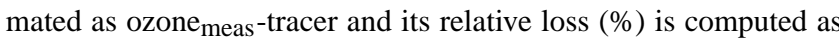
$100 \times\left(\right.$ ozone $_{\text {meas }}$-tracer $) /$ tracer. The dotted vertical line represents July 1 , and the horizontal lines show 50 and 150 DU and 15, 30 and $45 \%$ of ozone loss.

ozone loss estimated from Rio Gallegos, Kerguelen and Macquarie Island ozone measurements in 2005-2009. Extension of the vortex to the mid-latitudes was absent in some years, as in 2005 at Macquarie Island and in 2008 at Kerguelen. Further, there were no vortex events found over Lauder during recent winters.

The analyses expose the vortex overpasses for a few days in October 2008 and November 2009 and show a maximum ozone loss of 40-45\% (150-200 DU) at Rio Gallegos. A similar scale $(30-50 \%)$ of reduction from a higher number of vortex occurrences at Ushuaia is also estimated with the SLIMCAT tracer in September-November 2004-2008 (not shown). Except in 2008, about 30\% (50-100 DU) of ozone depletion is observed at Kerguelen during the vortex events in October-November of the recent winters. Conversely, passage of the vortex over Macquarie Island was found mostly during early winter and the observed ozone loss was about $10-20 \%$ (up to 100 DU) in 2006-2009. Nevertheless, this is equal to that of the Antarctic during the same period.

In order to analyse the inter-annual variations, the October mean of the total ozone from selected mid-latitude stations are examined in Fig. 10. There is a weak signal of ozone reduction ( 50 DU) in 1975-1993 at Lauder and Macquarie Island, in agreement with previous studies of Harris et al. (2003) for the former and Chubachi (2009) for the latter. The measurements at Perth and Buenos Aires also show some reduction in ozone during the period (Kane, 1991, 2008). 


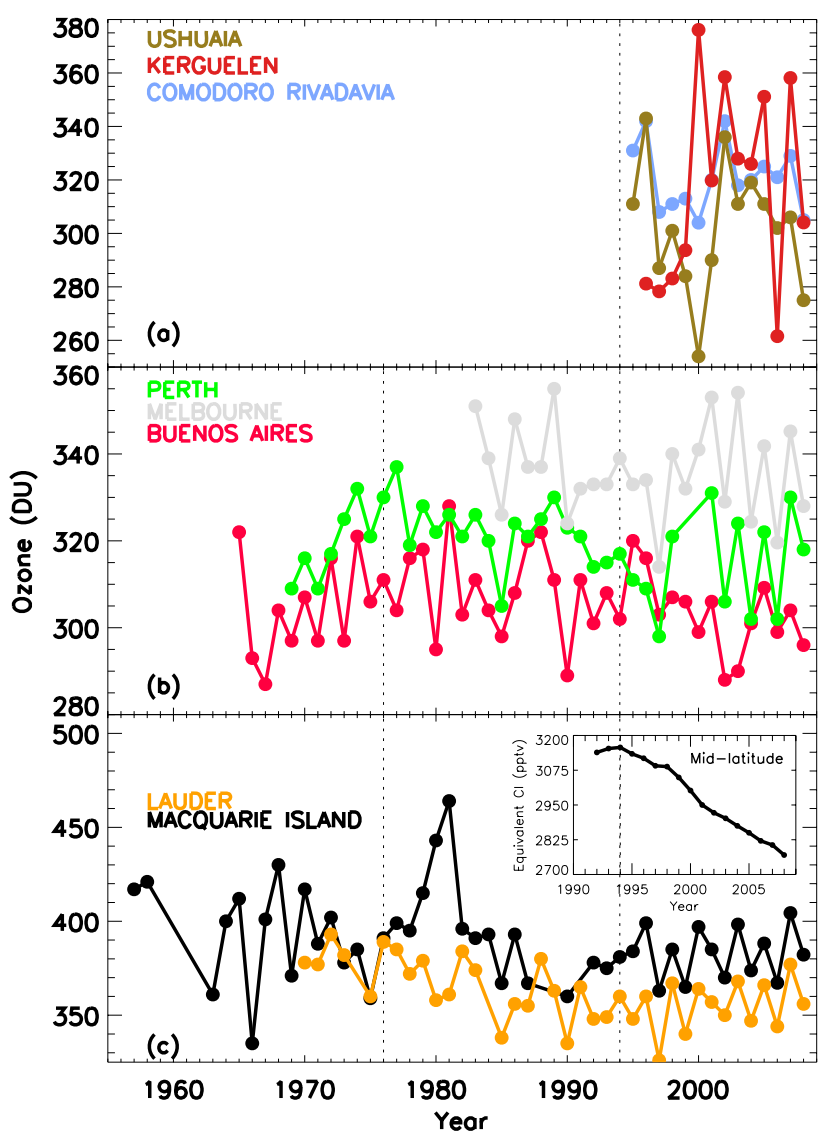

Fig. 10. Evolution of October mean total ozone from southern mid-latitude ground-based stations (a) stations installed after 1985, (b) historical stations at $30-40^{\circ} \mathrm{S}$, and (c) historical stations at 40 $60^{\circ} \mathrm{S}$ with equivalent chlorine in the mid-latitude in the inset. The dotted vertical lines represent years 1976 and 1994.

These results are consistent with the well established mean $5 \%$ depletion in the southern mid-latitudes since the preozone hole period (WMO, 2007). Nevertheless, the time series of Melbourne is too short to deduce a significant trend. As expected, the measurements at Ushuaia, Comodoro Rivadavia and Kerguelen exhibit large inter-annual variations due to the episodic vortex exposures.

\section{Conclusions}

The passive method is shown to provide ozone loss estimations within an accuracy of about $4 \%$ and is applied to evaluate ozone loss from the ground-based measurements in the Antarctic winters 2005-2009. The depletion is shown to start at the edge of the vortex by July in every winter and each station shows different timing for the onset of ozone loss depending on its exposure to sunlight. Further, the magnitude of loss is also different at each station in line with the temperature, PV, PSCs, and prevailing heterogeneous chem- istry, which is quite in agreement with our current understanding of polar wintertime chemistry. In accordance with previous studies, the ground-based stations show substantial ozone loss of around 55\% since 2005. However, the year-toyear differences in ozone loss are not large in the Antarctic, consistent with earlier studies. The ozone loss and loss rates computed from OMI and SCIA observations compare well with that of the ground-based measurements (within $\pm 2 \%$ ). The CTMs imitate well the ozone depletion features and reproduce the maximum loss within $\pm 3 \%$ difference.

The October average of the total column measurements at the historical ground-based stations do show that the depletion started in the late 1970s. The ozone reduction peaked in the early 1990s and stabilised afterwards until present due to its saturation. The analyses indicate no clear sign of significant ozone recovery yet. Another important feature is the effect of the ozone hole at southern mid-latitudes. The SAOZ measurements at Kerguelen and Rio Gallegos, the first observations from the latter, reveal severe ozone loss $(20-45 \%$ or 50-200 DU) episodes, which reiterates the value of observations in southern mid-latitudes.

This study shows that, the maintenance of an efficient ground-based network independent of satellites, particularly UV-VIS that are capable of making observations in earlywinter, is inevitable for monitoring the long term evolution of the ozone hole and its anticipated recovery from the reduced chlorofluorocarbon (CFC) emissions.

Acknowledgements. We thank Udo Frieß of Institute for Environmental Physics, Uni-Heidelberg, Germany for the Neumayer data, Jonathan Shanklin, British Antarctic Survey (BAS) for the BAS Antarctic stations data, Eric Nash of NASA GSFC for the vortex edge data, Cathy Boonne of Centre for Atmospheric Chemistry Products and Services (ETHER) for providing with MIMOSA PV and REPROBUS ozone and tracer data, and Eduardo Quel, Elian Wolfram and, Jacobo Salvador of CEILAP (CITEFA-CONICET) for the Rio Gallegos data. The participation of BAS in this study is part of BAS's Polar Science for Planet Earth programme, funded by the Natural Environment Research Council of UK. The OMI data are retrieved from Aura Validation Data Center of NASA (http://avdc.gsfc.nasa.gov) and the SCIAMACHY data obtained from TEMIS web interface (http://www.temis.nl). The EESC data for the Antarctic and mid-latitudes were obtained from NOAA website (http://www.esrl.noaa.gov/gmd/odgi/). The data used in this publication were obtained as part of the Network for the Detection of Atmospheric Composition Change (NDACC) and are publicly available (see http://www.ndacc.org). The French stations are supported by IPEV (Institut Paul Emile Victor), INSU (Institut des Sciences de l'Univers) and CNES (Centre National d'Etudes Spatiales). A good part of the data used in this work is also taken from World Ozone and Ultraviolet Radiation Data Centre (WOUDC) and are publicly available (see http://www.woudc.org). We take this opportunity to thank the respective national governing bodies, research establishments and station scientists, who maintain the stations. The work was supported by a funding from French ANR/ORACLE and EC/SCOUT-O 3 projects.

Edited by: M. Dameris 


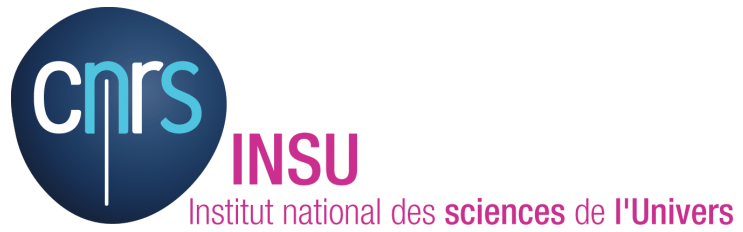

The publication of this article is financed by CNRS-INSU.

\section{References}

Andersen, S. B. and Knudsen, B. M.: The influence of polar vortex ozone depletion on NH mid-latitude ozone trends in spring, Atmos. Chem. Phys., 6, 2837-2845, doi:10.5194/acp-6-28372006, 2006.

Basher, R. E.: Review of the Dobson spectrophotometer and its accuracy, WMO Global Ozone Research and Monitoring Project, Report No. 13, WMO, Geneva, 1982.

Bevilacqua, R. M., Debrestianet, D. J, Aellig, C. P., et al.: POAM II ozone observations in the Antarctic ozone hole in 1994, 1995, and 1996, J. Geophys. Res., 102(D19), 23643-23657, doi:10.1029/97JD01623, 1997.

Bhartia, P. K. and Wellemeyer, C. W.: TOMS-V8 total $\mathrm{O}_{3}$ algorithm, NASA Goddard Space Flight Centre, Greenbelt, MD, OMI Algorithm, Theoretical Basis Document Vol. II., 2387 pp., 2002.

Boccara, G., Hertzog, A., Basdevant, C., and Vial, F.: Accuracy of NCEP/NCAR reanalyses and ECMWF analyses in the lower stratosphere over Antarctica in 2005, J. Geophys. Res., 113, D20115, doi:10.1029/2008JD010116, 2008.

Bodeker, G. E., Scott, J. C., Kreher, K., and McKenzie, R. L.: Global ozone trends in potential vorticity coordinates using TOMS and GOME inter-compared against the Dobson network: 1978-1998, J. Geophys. Res., 106, 23029-23042, doi:10.1029/2001JD900220, 2001.

Bojkov, R. D., and Fioletov, V. E.: Estimating the global ozone characteristics during the last 30 years, J. Geophys. Res., 100(D8), 16537-16551, doi:10.1029/95JD00692, 1995.

Bojkov, R. D., Bishop, L., and Fioletov, V. E.: Total ozone trends from quality-controlled ground-based data (1964-1994), J. Geophys. Res., 100(D12), 25867-25876, doi:10.1029/95JD02907, 1995.

Bovensman, H., Burrows, J. P., Buchwitz, M., Frerick, J., Noël, S., Rozanov, V. V., Chance, K. V., and Goede, A. P. H.: SCIAMACHY: mission objectives and measurement modes, J. Atmos. Sci., 56, 127-150, 1999.

Brewer, A. W.: A replacement for the dobson spectrophotometer?, Pure Appl. Geophys., 919(1136), 106-108, 1973.

Burkholder, J. B., Orlando, J. J., and Howard, C. J.: Ultraviolet absorption cross-sections of $\mathrm{Cl}_{2} \mathrm{O}_{2}$ between 210 and $410 \mathrm{~nm}, \mathrm{~J}$. Phys. Chem., 94, 687-695, 1990.

Chipperfield, M. P.: Multiannual simulations with a ThreeDimensional chemical transport model, J. Geophys. Res., 104, 1781-1805, 1999.

Chipperfield, M. P.: New version of the TOMCAT/SLIMCAT offline chemical transport model: Inter-comparison of stratospheric tracer experiments, Q. J. Roy. Meteorol. Soc., 132, 1179-1203, doi:10.1256/qj.05.51, 2006.
Chubachi, S.: Seasonal start of the Antarctic ozone hole derived from observations with Dobson spectrophotometers, Int. J. Remote Sens., 30, 3907-3916, doi:10.1080/01431160902821957, 2009.

Davies, S., Chipperfield, M. P., Carslaw, K. S., and et al.: Modelling the effect of denitrification on Arctic ozone depletion during winter 1999/2000, J. Geophys. Res., 107, 8322, doi:10.1029/2001JD000445, 2002.

Dobson, G. M. B.: Observer's handbook for the ozone spectrophotometer, Ann. Int. Geophys. Year 5, 46-89, 1957.

Eskes, H. J., van der A. R. J., Brinksma, E. J., Veefkind, J. P., de Haan, J. F., and Valks, P. J. M.: Retrieval and validation of ozone columns derived from measurements of SCIAMACHY on Envisat, Atmos. Chem. Phys. Discuss., 5, 4429-4475, 2005, http://www.atmos-chem-phys-discuss.net/5/4429/2005/.

Farman, J. C., Gardiner, B. G., and Shanklin, J. D.: Large losses of total ozone in Antarctica reveal seasonal $\mathrm{ClO}_{\mathrm{X}} / \mathrm{NO}_{\mathrm{x}}$ interaction, Nature, 315, 207-210, 1985.

Feng, W., M. P. Chipperfield, H. K. Roscoe, J. J. Remedios, A. M. Waterfall, G. P. Stiller, N. Glatthor, M. Höpfner, D-Y. Wang: Three-Dimensional Model Study of the Antarctic Ozone Hole in 2002 and Comparison with 2000, J. Atmos. Sci., 62, 822-837, $2005 a$.

Feng, W., Chipperfield, M. P., Davies, S., Sen, B., Toon, G., Blavier, J. F., Webster, C. R., Volk, C. M., Ulanovsky, A., Ravegnani, F., von der Gathen, P., Jost, H., Richard, E. C., and Claude, H.: Three-dimensional model study of the Arctic ozone loss in 2002/2003 and comparison with 1999/2000 and 2003/2004, Atmos. Chem. Phys., 5, 139-152, doi:10.5194/acp-5-139-2005, $2005 b$.

Feng W., M. P. Chipperfield, S. Davies, P. von der Gathen, E. Kyro, C. M. Volk, A. Ulanovsky and G. Belyaev: Large chemical ozone loss in 2004/05 Arctic winter/spring, Geophys. Res. Lett., 34, L09803, doi:10.1029/2006GL029098, 2007a.

Feng, W. Chipperfield, M. P., Dorf, M., Pfeilsticker, K and P. Ricaud: Mid-latitude ozone changes: Studies with a 3-D CTM forced by ERA-40 analyses, Atmos. Chem. Phys., 7, 2357-2369, doi:10.5194/acp-7-2357-2007, 2007 b.

Fioletov, V. E., Bodeker, G. E., Miller, A. J., McPeters, R. D. and Stolarski, R.: Global and zonal total ozone variations estimated from ground based and satellite measurements: 1964-2000, J. Geophys. Res. 107(D22), 4647, doi:10.1029/2001JD001350., 2002.

Frieß, U., Kreher, K., Johnston, P. V., and Platt, U.: Ground-based DOAS measurements of stratospheric trace gases at two Antarctic stations during the 2002 ozone hole period, J. Atmos. Sci., 62, 765-777, 2005.

Goutail, F., Pommereau, J.-P., Phillips, C.. Deniel, C., Sarkissian, A., Lefevre, F., Kyro, E., Rummukainen, M., Ericksen, P., Andersen, S., Kåstad Høiskar, B.-A., Braathen, G., Dorokhov, V., and Khattatov, V.: Depletion of column ozone in the Arctic during the Winters 1993-94 and 1994-95, J. Atmos. Chem., 32, 134, 1999.

Harris J. M., Oltmans S. J., Bodeker G. E., Stolarski R., Evans R. D., and Quincy D. M.: Long-term variations in total ozone derived from Dobson and satellite data, Atmos. Environ., 37, 3167-3175, 2003.

Hauchecorne, A., Godin, S., Marchand, M., Heese, B., and Souprayen, C.: Quantification of the transport of chemical con- 
stituents from the polar vortex to mid-latitudes in the lower stratosphere using the high-resolution advection model MIMOSA and effective diffusivity, J. Geophys. Res., 107(D20), 8289, doi:10.1029/2001JD000491, 2002.

Hofmann, D. J., Oltmans, S. J., Harris, J. M., Johnson, B. J., and Lathrop, J. A.: Ten years of ozonesonde measurements at the south pole: Implications for recovery of springtime Antarctic ozone, J. Geophys. Res., 102, 8931-8943, doi:10.1029/96JD03749, 1997.

Hoppel, K., Nedoluha, G., Fromm, M., Allen, D., Bevilacqua, R., Alfred, J., Johnson, B., and König-Langlo, G.: Reduced ozone loss at the upper edge of the Antarctic Ozone Hole during 2001-2004, Geophys. Res. Lett., 32, L20816, doi:10.1029/2005GL023968, 2005.

Huck, P. E., Tilmes, S., Bodeker, G. E., Randel, W. J., McDonald, A. J., and Nakajima, H.: An improved measure of ozone depletion in the Antarctic stratosphere, J. Geophys. Res., 112, D11104, doi:10.1029/2006JD007860, 2007.

Kane, R. P: Extension of Antarctic ozone hole to lower latitudes in the South American region, PAGEOPH, 135, 611-624, 1991.

Kane, R. P: Is ozone depletion really recovering?, J. Atmos. Solar Terr. Phys., 70, 1455-1459, 2008.

Lee, A. M., Roscoe, H. K., and Oltmans, S.: Model and measurements show Antarctic ozone loss follows edge of polar night, Geophys. Res. Lett., 27, 3845-3848, doi:10.1029/2000GL01144, 2000.

Lefèvre, F., Brasseur, G. P., Folkins, I., Smith, A. K., and Simon, P.: Chemistry of the $1991 / 1992$ stratospheric winter: three dimensional model simulation, J. Geophys. Res., 99, 8183-8195, 1994.

Lefèvre, F., Figarol, F., Carslaw, K. S., and Peter, T.: The 1997 Arctic ozone depletion quantified from three dimensional model simulations, Geophys. Res. Lett., 25, 2425-2428, 1998.

Lemmen, C., Dameris, M., Müller, R., and Riese, M.: Chemical ozone loss in a chemistry-climate model from 1960 to 1999 , Geophys. Res. Lett., 33, L15820, doi:10.1029/2006GL026939, 2006

Levelt, P. F., van den Oord, G. H. J., Dobber, M. R., Mlkki, A., Visser, H., de Vries, J., Stammes, P., Lundell, J., and Saari, H.: The Ozone Monitoring Instrument, IEEE T. Geosci. Remote Sens., 44, 1093-1101, 2006.

Luo, B., Carslaw, K. S., Peter, T., Clegg, S.L.: Vapour pressures of $\mathrm{H}_{2} \mathrm{SO}_{4} / \mathrm{HNO}_{3} / \mathrm{HCl} / \mathrm{HBr} / \mathrm{H}_{2} \mathrm{O}$ solutions to low stratospheric temperatures, Geophys. Res. Lett., 22, 247-250, 1995.

Nash, E. R., Newman, P. A., Rosenfield, J. E., and Schoeberl, M. R.: An objective determination of the polar vortex using Ertel's potential vorticity, J. Geophys. Res., 101, 9471-9478, 1996.

Pitts, M. C., Thomason, L. W., Poole, L. R., and Winker, D. M.: Characterization of Polar Stratospheric Clouds with spaceborne lidar: CALIPSO and the 2006 Antarctic season, Atmos. Chem. Phys., 7, 5207-5228, doi:10.5194/acp-7-5207-2007, 2007.
Pommereau, J.-P. and Goutail, F.: Stratospheric $\mathrm{O}_{3}$ and $\mathrm{NO}_{2} \mathrm{Ob}$ servations at the Southern Polar Circle in Summer and Fall 1988, Geophys. Res. Lett., 15, 891-894, 1988.

Prather, M. J.: Numerical advection by conservation of secondorder moments, J. Geophys. Res., 91, 6671-6681, 1986.

Roscoe, H. K, Johnston, P. V., Van Roozendael, M., Richter, A., Preston, K., Lambert, J. C., Hermans, C., de Kuyper, W., Dzenius, S., Winterath, T., Burrows, J., Sarkissian, A., Goutail, F., Pommereau, J.-P., et al.: Slant column measurements of $\mathrm{O}_{3}$ and $\mathrm{NO}_{2}$ during the NDSC Intercomparison of zenith-sky UVvisible spectrometers in June 1996, J. Atmos. Chem., 32, 281314, 1999.

Sander, S. P., Friedl, R. R., Golden, D. M., et al.: Chemical kinetics and photochemical data for use in atmospheric studies, Eval. 15, JPL Publ. 06-2, Jet Propul. Lab., Pasadena, USA, 2006.

Solomon, S., Portmann, R. W., Sasaki, T., Hofmann, D. J., and Thompson, D. W. J.: Four decades of ozonesonde measurements over Antarctica, J. Geophys. Res., 110, D21311, doi:10.1029/2005JD005917, 2005.

Tilmes, S., Mueller, R., Grooß, J.-U., Spang, R., Sugita, T., Nakajima, H., and Sasano, Y.: Chemical ozone loss and related processes in the Antarctic winter 2003 based on Improved Limb Atmospheric Spectrometer (ILAS)-II observations, J. Geophys. Res., 111, D11S12, doi:10.1029/2005JD006260, 2006.

Vaughan, G., Roscoe, H., Bartlett, K., and et al.: An intercomparison of ground-based $\mathrm{UV}$ visible sensors of Ozone and $\mathrm{NO}_{2}, \mathrm{~J}$. Geophys. Res., 102, 1411-1422, 1997.

Vyushin, D. I., Fioletov, V. E., and Shepherd, T. G.: Impact of longrange correlations on trend detection in total ozone, J. Geophys. Res., 112, D14307, doi:10.1029/2006JD008168, 2007.

Williamson, D. L. and Rasch, P. J.: Two-dimensional semiLagrangian transport with shape-preserving interpolation, Mon Weather Rev., 117, 102-129, 1989.

WMO (World Meteorological Organisation): The Global Atmosphere Watch Guide, WMO TD No. 553, 1993.

WMO (World Meteorological Organisation): Scientific assessment of ozone depletion: 2006, Global Ozone Research and Monitoring Project-Report No. 50, 572 pp., Geneva, Switzerland, 2007.

Wu, J. and Dessler A. E.: Comparisons between measurements and models of Antarctic ozone loss, J. Geophys. Res., 106(D3), 3195-3201, 2001

Yang, E.-S., Cunnold, D. M., Newchurch, M. J., Salawitch, R., McCormick, J. M. P., Russell III, J. M., Zawodny, J. M., and Oltmans, S. J.: First stage of Antarctic ozone recovery, J. Geophys. Res., 113, D20308, doi:10.1029/2007JD009675, 2008. 